\title{
Treatment of Metastatic Colorectal Cancer: Standard of Care and Future Perspectives
}

\author{
Julian Holch ${ }^{\mathrm{a}, \mathrm{b}}$ Sebastian Stintzing ${ }^{\mathrm{a}} \quad$ Volker Heinemann ${ }^{\mathrm{a}, \mathrm{b}}$ \\ ${ }^{a}$ Department of Internal Medicine III, Klinikum der Universität München, Ludwig-Maximilians-Universität (LMU), Munich, Germany;

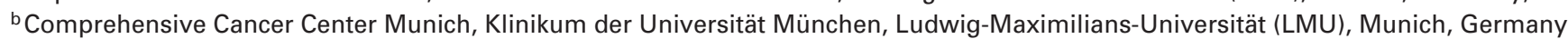

\section{Keywords}

Metastatic colorectal cancer · Palliative chemotherapy ·

RAS mutation - BRAF mutation

\section{Summary}

Palliative chemotherapy for metastatic colorectal cancer has undergone substantial changes in recent years. The implementation of modern biologicals in the treatment has substantially improved overall survival up to 30 months. With the increasing number of therapeutic options, the question of optimal treatment sequence arises, which is addressed in current studies like FIRE 4 or STRATEGIC-1. Furthermore, clinical and molecular biomarkers to predict efficacy and tolerability are urgently needed. Today, the detection of activating RAS mutations is the only validated biomarker which precludes patients from anti-EGFR treatment. The detection of BRAF mutation $\mathrm{V} 600 \mathrm{E}$ is associated with a very poor prognosis corresponding to a survival of 9-12 months. Prospective trials evaluating an optimal approach to this subgroup are still missing. First results from strategies targeting the aberrant signal transduction are promising and require further validation. Despite the advances so far, life expectancy unfortunately continues to be limited in the majority of patients with metastatic colorectal cancer. New strategies are needed to improve the prognosis. To this end, the identification of Her2/neu as a potential target and first experiences with checkpoint inhibition in patients with mismatch repair-deficient tumors are promising and also require further validation.

(c) 2016 S. Karger GmbH, Freiburg

\section{Introduction}

Colorectal cancer is the third most frequent type of cancer in Germany with expected 61,000 newly diagnosed cases in 2016 [1]. The median age at diagnosis is about 70 years. Approximately $25 \%$ of the patients show synchronous metastases and 25\% develop metastases during the course of the disease [2]. Metastatic colorectal cancer (mCRC) has a critical prognosis with a 5 -year survival rate of less than $10 \%$ [3]. In Germany, mCRC leads to 26,000 deaths per year [1]. Treatment of mCRC has undergone substantial changes in the last 20 years. New therapeutics and combination regimens have led to marked improvements in both response rate (RR) and overall survival (OS). This article provides an overview of the current standard of care and future perspectives in the systemic treatment of mCRC.

\section{Choice of First-Line Treatment}

\section{General Aspects}

In general, the choice of first-line treatment should be influenced by the tolerability of the medication as well as the patient's comorbidities, biological age, and preferences. It is important to emphasize that decisions regarding the first-line treatment are crucial for the patient's outcome: first-line treatment has a significantly higher overall response rate (ORR) and longer progressionfree survival (PFS) than consecutive treatment lines [4]. Furthermore, the fraction of patients receiving chemotherapy decreases with each treatment line [5]. Finally, the choice of first-line treatment defines the possible consecutive regimens.

\section{Therapeutics and Regimens}

Standard of care for the majority of patients is the combination of 5-fluorouracil (FU)/leucovorin (LV) with either oxaliplatin (FOLFOX) or irinotecan (FOLFIRI) together with a monoclonal 
Table 1. Summary of important clinical trials in the authors' view (according to [4])

\begin{tabular}{|c|c|c|c|c|c|c|c|c|}
\hline Study & Phase & Treatment & $\mathrm{n}$ & $\begin{array}{l}\text { ORR, } \\
\%\end{array}$ & $\begin{array}{l}\text { PFS, } \\
\text { months }\end{array}$ & HR & $\begin{array}{l}\text { OS, } \\
\text { months }\end{array}$ & HR \\
\hline \multicolumn{9}{|l|}{ First-line studies } \\
\hline \multirow[t]{2}{*}{ Falcone et al. [8] } & \multirow[t]{2}{*}{ III } & FOLFIRI & 122 & 34 & 6.9 & \multirow[b]{2}{*}{0.63} & 16.7 & \multirow{2}{*}{0.70} \\
\hline & & FOLFOXIRI & 122 & 60 & 9.8 & & 22.6 & \\
\hline \multirow[t]{2}{*}{ Tournigand et al. [7] } & \multirow[t]{2}{*}{ III } & FOLFIRI & 109 & 56 & 8.5 & \multirow[b]{2}{*}{-} & 21.5 & \multirow[b]{2}{*}{-} \\
\hline & & FOLFOX & 111 & 54 & 8.1 & & 20.6 & \\
\hline \multirow[t]{2}{*}{ CRYSTAL $^{\mathrm{a}}[14]$} & \multirow[t]{2}{*}{ III } & FOLFIRI & 350 & 39.7 & 8.4 & \multirow[b]{2}{*}{0.696} & 20.0 & \multirow{2}{*}{$0.796^{\mathrm{C}}$} \\
\hline & & FOLFIRI + cetuximab & 316 & 57.3 & 9.9 & & 23.5 & \\
\hline \multirow[t]{2}{*}{ OPUS $^{\mathrm{a}}[15]$} & \multirow[t]{2}{*}{ II } & FOLFOX & 97 & 34.0 & 7.2 & \multirow[b]{2}{*}{0.567} & 18.5 & \multirow[b]{2}{*}{$0.855^{\mathrm{c}}$} \\
\hline & & FOLFOX + cetuximab & 82 & 57.3 & 8.3 & & 22.8 & \\
\hline \multirow[t]{2}{*}{ PRIME $^{\mathrm{b}}[16]$} & \multirow[t]{2}{*}{ III } & FOLFOX & 253 & - & 7.9 & \multirow[b]{2}{*}{0.72} & 20.2 & \multirow[b]{2}{*}{0.77} \\
\hline & & FOLFOX + panitumumab & 259 & - & 10.1 & & 25.28 & \\
\hline \multirow[t]{2}{*}{ NO16966 [10] } & \multirow[t]{2}{*}{ III } & FOLFOX/XELOX & 701 & 38.0 & 8.0 & & 21.3 & \\
\hline & & FOLFOX/XELOX + bevacizumab & 699 & 38.0 & 9.4 & 0.83 & 19.9 & $0.89^{c}$ \\
\hline Hurwitz et al. [17] & III & IFL + placebo & 411 & 34.8 & 6.2 & & 15.6 & \\
\hline & & IFL + bevacizumab & 402 & 44.8 & 10.6 & 0.62 & 20.3 & 0.66 \\
\hline FIRE-3 ${ }^{\mathrm{b}}[45,46]$ & III & FOLFIRI + cetuximab & 171 & 66 & 10.4 & & 33.1 & \\
\hline & & FOLFIRI + bevacizumab & 171 & 60 & 10.2 & $0.97^{\mathrm{c}}$ & 25.6 & 0.697 \\
\hline CALGB-80405 ${ }^{\mathrm{b}^{*}}[47]$ & III & chemotherapy + cetuximab & 270 & 68.6 & 11.4 & & 32.0 & \\
\hline & & chemotherapy + bevacizumab & 256 & 53.8 & 11.3 & $1.1^{\mathrm{c}}$ & 31.2 & $0.9^{c}$ \\
\hline PEAK $^{\mathrm{b}}[48]$ & II & FOLFOX + panitumumab & 88 & 63 & 13.0 & & 41.3 & \\
\hline & & FOLFOX + bevacizumab & 82 & 60 & 9.5 & 0.65 & 28.9 & $0.63^{c}$ \\
\hline TRIBE [9] & III & FOLFIRI + bevacizumab & 256 & 54 & 9.7 & & 25.8 & \\
\hline & & FOLFOXIRI + bevacizumab & 252 & 65 & 12.3 & 0.77 & 29.8 & 0.80 \\
\hline AVEX [13] & III & capecitabine & 140 & 10 & 5.1 & & 16.8 & \\
\hline & & capecitabine + bevacizumab & 140 & 19 & 9.1 & 0.53 & 20.7 & $0.79^{\mathrm{c}}$ \\
\hline Second and further lin & & & & & & & & \\
\hline E3200 [30] & III & FOLFOX & 291 & 8.6 & 4.7 & & 10.8 & \\
\hline & & FOLFOX + bevacizumab & 286 & 22.7 & 7.3 & 0.61 & 12.9 & 0.75 \\
\hline TML [31] & III & chemotherapy & 411 & 4 & 4.1 & & 9.8 & \\
\hline & & chemotherapy + bevacizumab & 409 & 5 & 5.7 & 0.68 & 11.2 & 0.81 \\
\hline VELOUR [32] & III & FOLFIRI & 614 & 11.1 & 4.7 & & 12.1 & \\
\hline & & FOLFIRI + aflibercept & 612 & 19.8 & 6.9 & 0.76 & 13.5 & 0.82 \\
\hline RAISE [33] & III & FOLFIRI + placebo & 536 & 72 & 4.5 & & 11.7 & \\
\hline & & FOLFIRI + ramucirumab & 536 & 67 & 5.7 & 0.793 & 13.3 & 0.844 \\
\hline CORRECT [35] & III & placebo + BSC & 255 & 0.4 & 1.7 & & 6.4 & \\
\hline & & regorafenib + BSC & 505 & 1.0 & 1.9 & 0.49 & 5.0 & 0.77 \\
\hline KRAS wild-type pop & & & & & & & & \\
\hline${ }^{b}$ RAS wild-type popul & & & & & & & & \\
\hline${ }^{c}$ Non-significant. & & & & & & & & \\
\hline${ }^{\star}$ Only data from $526 \mathrm{p}$ & & & & & & & & \\
\hline Presented hazard ratic & ant if no & otherwise indicated. & & & & & & \\
\hline Primary study end po & ed in ital & & & & & & & \\
\hline $\mathrm{BSC}=$ Best supportiv & jerall res & nse rate; $\mathrm{PFS}=$ progression -free su & $=$ haz & atio; $\mathrm{O}$ & overall s & & & \\
\hline
\end{tabular}

antibody $(\mathrm{moAb})$ against either vascular endothelial growth factor (VEGF) or epidermal growth factor receptor (EGFR) [6]. Bevacizumab is a moAb against VEGF, whereas cetuximab and panitumumab are directed against EGFR. All three are approved for firstline treatment in mCRC.

FOLFOX and FOLFIRI show a comparable efficacy regarding OS [7]. For clinically fit patients, a higher ORR and a longer OS can be achieved with the triple combination of FOLFOXIRI alone [8] or in combination with bevacizumab [9]. Intravenous 5-FU can be replaced by the oral fluoropyrimidine capecitabine either in combination with oxaliplatin (CapOx) [10] or irinotecan (CapIri) [11]. In general, capecitabine should not be combined with cetuximab due to negative results obtained in the COIN study [12]. Especially for elderly patients, the combination of capecitabine and bevacizumab is effective and well tolerated [13].

Cetuximab and panitumumab are both approved for first-line treatment with either FOLFIRI or FOLFOX [14-16]. The approval of bevacizumab in the first-line setting is based on a phase III trial 
Fig. 1. Possible approach to choose first-line treatment for patients with $\mathrm{mCRC}$ (adapted according to the ESMO Pocket Guidelines 2015 Lower Gastrointestinal

Cancer, Section metastatic colorectal cancer). FP = Fluoropyrimidin; $\mathrm{CT}=$ chemotherapy.

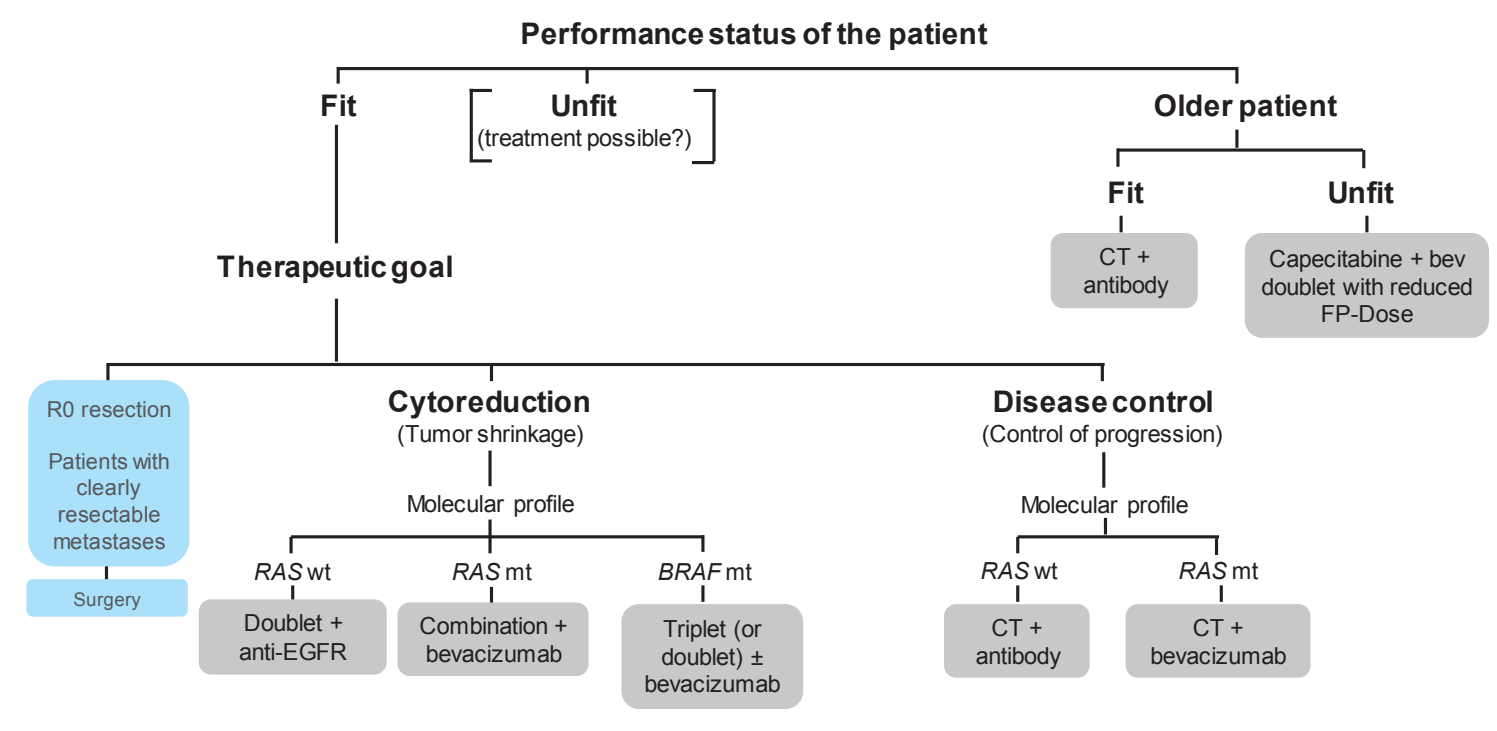

using an irinotecan-containing combination (IFL), which is no longer common due to toxicity $[17,18]$. A study evaluating bevacizumab first-line in combination with oxaliplatin-based regimens could only demonstrate a benefit regarding PFS, while it was minor and non-significant concerning OS [10]. The optimal sequence of anti-EGFR and anti-VEGF strategy in patients without corresponding contraindications is still under debate and warrants further investigation. Key studies of this review are summarized in table 1.

\section{Predictive and Prognostic Factors}

So far, the only established predictive biomarker in the treatment of $\mathrm{mCRC}$ is the detection of activating mutations in KRAS (Kirsten RAS) or NRAS (neuroblastoma RAS) oncogene. These mutations occur in about $50 \%$ of mCRC and affect exons $2-4$ in both genes [16]. Activated RAS can bypass the antiproliferative effects of antiEGFR antibodies and patients with RAS mutation do not profit from such treatment $[16,19]$. In combination with oxaliplatin, anti-EGFR treatment could even harm these patients [16]. Hence, testing the patient's tumor samples for RAS mutation is obligatory [6]. Cetuximab and panitumumab are contraindicated if a RAS mutation is detected. This also includes KRAS p.G13D mutation since more recent evidence indicates that also this subgroup does not benefit from the addition of cetuximab to chemotherapy [20,21].

Besides testing for RAS mutation, the expected ESMO Clinical Practice Guidelines (initial presentation at the ECC conference 2015) will also advise to test for BRAF mutation V600E in patients with $\mathrm{mCRC}$. This mutation can be found in $8-10 \%$ of patients and is associated with a poor prognosis $[16,22]$.

\section{Treatment of Patients with RAS-Mutated Tumors}

Patients with RAS-mutated tumor have fewer treatment options because anti-EGFR strategies are contraindicated. While optimal treatment of this subgroup is unclear, chemotherapy is mostly combined with bevacizumab in the first-line setting. Taking into account the results of the TML trial, the continuation of treatment with bevacizumab beyond first progression leads to a moderate but statistically significant prolongation of OS irrespective of KRAS mutation status [23].

\section{Treatment of Patients with RAS Wild-Type Tumors}

For patients without RAS mutation all approved first-line options are available. Whether optimal first-line treatment should contain an anti-EGFR or an anti-VEGF agent has recently been the focus of a controversial debate. Altogether, three trials address this question: FIRE-3, CALGB-80405, and PEAK (for details see table 1). A metaanalysis taking the three trials into account shows superior ORR and OS with first-line anti-EGFR therapy compared with anti-VEGF therapy. According to these results, it seems reasonable to initiate treatment of RAS wild-type patients with an anti-EGFR strategy [4], especially if tumor shrinkage is the primary aim [24].

\section{Treatment of Patients with BRAF Mutation}

The prognosis of patients with BRAF mutation is very poor with a median OS of $9-14$ months $[9,15,22]$. In this subgroup, the TRIBE study comparing bevacizumab plus either FOLFIRI or FOLFOXIRI revealed a profound benefit for the more intensive regimen and should be considered in these patients [9].

\section{Treatment of Patients with Resectable Metastases}

For patients with primarily resectable liver or lung metastases, upfront resection is an option, especially if metastases are limited in number and size [6]. In the EPOC study, perioperative chemotherapy with FOLFOX has increased PFS (primary end point) without significant impact on OS [25]. The approach to these patients should ideally be defined in a multidisciplinary team taking the individual patient's context into account [4]. After complete resection of colorectal metastases, some evidence suggests an additive 5-FU-based chemotherapy [26]. According to the results of the recent New EPOC study, patients with resectable liver metastases should not be treated with cetuximab plus chemotherapy [27].

Figure 1 indicates a possible approach to choose first-line treatment for patients with mCRC. 


\section{FIRE-4 (AIO KRK-0114) \\ )}

- firre $\mathbf{A l O}$

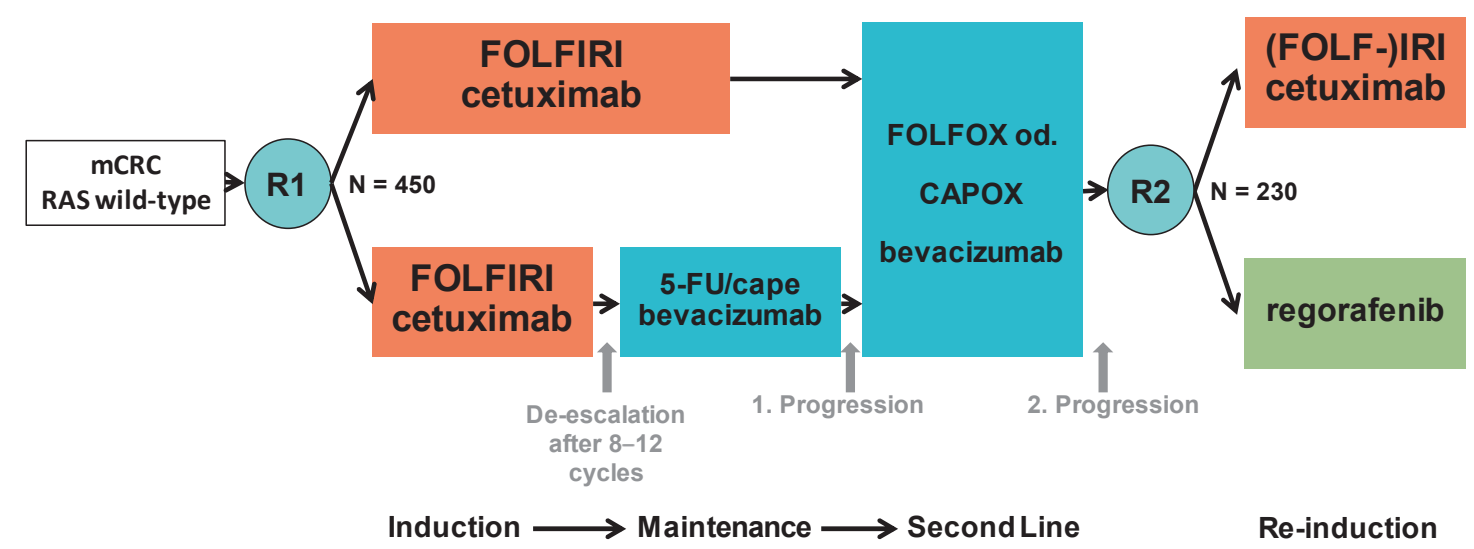

Fig. 2. Study design of the FIRE-4 (AIO KRK-0114) trial.
Induction $\longrightarrow$ Maintenance $\longrightarrow$ Second Line
Re-induction

\section{Strategy after Initial Treatment}

\section{Maintenance Therapy}

Especially in the context of oxaliplatin-containing regimens, the duration is frequently limited due to cumulative neurotoxicity. Hence, several studies have examined a strategy with de-escalation after an initial treatment phase followed by a maintenance therapy with re-escalation in the case of progressive disease. For 5-FU/LV/ oxaliplatin combinations with bevacizumab, two phase III trials have demonstrated that an active maintenance therapy (with fluoropyrimidine and bevacizumab) moderately prolongs PFS without significantly improving OS $[28,29]$. In regard of the results of the CAIRO 3 trial, 4.5 months should be regarded as the optimum duration of induction therapy [29].

\section{Later-Line Therapy}

Second-line treatment depends on the combination of chemotherapy and biological in the first-line setting and should counteract an occurred resistance. This includes switching oxaliplatinbased to irinotecan-based treatment as well as anti-EGFR to antiVEGF biological or vice versa. For example, FOLFOX plus bevacizumab yields a significant benefit regarding OS [30]. Of note, the continuation of bevacizumab after first progression has shown a significant benefit regarding OS [31]. Furthermore, the antiangiogenic fusion protein aflibercept in combination with FOLFIRI can prolong OS after progression upon an oxaliplatin-containing chemotherapy irrespective of previous bevacizumab usage [32]. With ramucirumab, an anti-VEGFR-2 antibody, the Food and Drug Administration has recently approved another beneficial second-line option in combination with FOLFIRI [33]. If not previously given, cetuximab and panitumumab are active as single agents in chemorefractory patients with comparable clinical activity [34]. After failure of the standard treatment options, the multi- target tyrosine kinase inhibitor regorafenib has shown a significant prolongation of OS in the last-line setting [35]. Due to a decision of the pharmaceutical company Bayer AG, regorafenib is no longer available in Germany as of April 15, 2016.

In later treatment lines, a rechallenge with cetuximab can be discussed if patients had achieved a good objective response during first-line treatment with this moAb [36]. The current phase III trial FIRE-4 investigates this strategy prospectively. A maintenance strategy is also incorporated into the innovative study design (fig. 2). Another study which also addresses optimal treatment sequence is the STRATEGIC-1 trial [37].

\section{Future Perspectives}

\section{Patients with BRAF Mutation}

Patients with activating BRAF mutation have a dismal prognosis even if treated with intensive chemotherapy. Hence, new strategies are urgently needed. First results from targeting the aberrant signal transduction are promising, albeit the usage of a single BRAF inhibitor has no beneficial effect due to positive feedback activation of EGFR [38, 39]. To overcome this, a pilot study examined the feasibility and efficacy of BRAF inhibitor vemurafenib combined with panitumumab [40]. Toxicity was manageable with less cutaneous side effects than would be expected with either agent. Clinical activity was moderate with an ORR of $17 \%$. This could be augmented by further combining BRAF inhibitor dabrafenib with panitumumab and MEK inhibitor trametinib in a phase I/II study leading to an ORR of $26 \%$ with a median PFS of 4.1 months in heavily pretreated patients [41]. With this combination, no grade IV toxicity was observed. These promising results need to be validated in further trials. 


\section{Checkpoint Inhibition}

Inhibition of the immune checkpoint PD-1 revealed disappointing results in patients with mCRC [42]. In contrast, patients whose tumor showed a mismatch repair deficiency (MMD) derived a clinical benefit from PD-1 blockade with pembrolizumab in a phase II trial [43]. Median PFS and OS were not reached in patients suffering from $\mathrm{mCRC}$ with MMD but were 2.2 and 5.0 months, respectively, in the cohort comprising mCRC without MMD (hazard ratio $0.1(\mathrm{p}<0.001)$ and $0.22(\mathrm{p}=0.05)$, respectively). In this study, MMD status was associated with a high somatic mutation load, which could serve as predictive biomarker for checkpoint inhibition, irrespective of the underlying tumor entity.

\section{Her2/neu}

About $5 \%$ of mCRC show an overexpression of Her $2 /$ neu. A phase II trial evaluated the treatment with trastuzumab and lapatinib in this subgroup and found a considerable clinical efficacy in heavily pretreated patients [44]. The primary end point was met with an ORR of $34.7 \%$. Disease control rate was $78 \%$. Treatment was well tolerated with no grade $4-5$ toxicity. These results deserve further clinical assessment to validate Her2/neu as a predictive factor for the corresponding targeted therapy.

\section{Disclosure Statement}

\section{J. Holch: No disclosures.}

S. Stintzing: Honoraria for talks and advisory boards: Merck KGaA, Roche AG, Bayer, Amgen, and Sanofi. Travel expenses to meetings: Merck KGaA, Roche AG, Bayer, Amgen, and Sanofi.

V. Heinemann: Advisory boards: Merck KGaA, Roche AG, Amgen, Sanofi, Lilly, SIRTEX, Böhringer Ingelheim, Baxalta, Taiho, and Merrimack. Honoraria for talks: Merck KGaA, Roche AG, Amgen, Sanofi, SIRTEX, and Baxalta. Travel expenses to meetings: Merck KGaA, Roche AG, Amgen, Sanofi, SIRTEX, and Baxalta.

\section{References}

1 Robert Koch-Institut (Hrsg), Gesellschaft der epidemiologischen Krebsregister in Deutschland e.V. (Hrsg): Krebs in Deutschland 2011/2012, ed 10. Berlin, 2015.

2 Bruckner HW, Motwani BT: Chemotherapy of advanced cancer of the colon and rectum. Semin Oncol 1991;18:443-461.

3 O'Connell JB, Maggard MA, Ko CY: Colon cancer survival rates with the new American Joint Committee on Cancer sixth edition staging. J Natl Cancer Inst 2004; 96:1420-1425.

4 Modest DP, Hiddemann W, Heinemann V: Chemotherapy of metastatic colorectal cancer (article in German). Internist (Berl) 2014;55:37-42.

5 Modest DP, Stintzing S, von Weikersthal LF, Decker T, Kiani A, Vehling-Kaiser U, Al-Batran SE, Heintges T, Lerchenmuller C, Kahl C, Seipelt G, Kullmann F, Stauch M, Scheithauer W, Held S, Mohler M, Jung A, Kirchner T, Heinemann V: Impact of subsequent therapies on outcome of the FIRE-3/AIO KRK0306 trial: first-line therapy with FOLFIRI plus cetuximab or bevacizumab in patients with KRAS wild-type tumors in metastatic colorectal cancer. J Clin Oncol 2015;33: 3718-3726.

6 Van Cutsem E, Cervantes A, Nordlinger B, Arnold D: Metastatic colorectal cancer: ESMO Clinical Practice Guidelines for diagnosis, treatment and follow-up. Ann Oncol 2014;25(suppl 3):iiil-9.

7 Tournigand C, Andre T, Achille E, Lledo G, Flesh M, Mery-Mignard D, Quinaux E, Couteau C, Buyse M, Ganem G, Landi B, Colin P, Louvet C, de Gramont A: FOLFIRI followed by FOLFOX6 or the reverse sequence in advanced colorectal cancer: a randomized GERCOR study. J Clin Oncol 2004;22:229-237.

8 Falcone A, Ricci S, Brunetti I, Pfanner E, Allegrini G Barbara C, Crino L, Benedetti G, Evangelista W, Fanchini L, Cortesi E, Picone V, Vitello S, Chiara S, Granetto C, Porcile G, Fioretto L, Orlandini C, Andreuccetti M, Masi G: Phase III trial of infusional fluorouracil, leucovorin, oxaliplatin, and irinotecan (FOLFOXIRI) compared with infusional fluorouracil, leucovorin, and irinotecan (FOLFIRI) as first-line treatment for metastatic colorectal cancer: the Gruppo Oncologico Nord Ovest. J Clin Oncol 2007;25:1670-1676.
9 Cremolini C, Loupakis F, Antoniotti C, Lupi C, Sensi E, Lonardi S, Mezi S, Tomasello G, Ronzoni M, Zaniboni A, Tonini G, Carlomagno C, Allegrini G, Chiara S, D’Amico M, Granetto C, Cazzaniga M, Boni L, Fontanini G, Falcone A: FOLFOXIRI plus bevacizumab versus FOLFIRI plus bevacizumab as first-line treatment of patients with metastatic colorectal cancer: updated overall survival and molecular subgroup analyses of the open-label, phase 3 TRIBE study. Lancet Oncol 2015;16:1306-1315.

10 Saltz LB, Clarke S, Diaz-Rubio E, Scheithauer W, Figer A, Wong R, Koski S, Lichinitser M, Yang TS, Rivera F, Couture F, Sirzen F, Cassidy J: Bevacizumab in combination with oxaliplatin-based chemotherapy as first-line therapy in metastatic colorectal cancer: a randomized phase III study. J Clin Oncol 2008;26:2013-2019.

11 Ducreux M, Adenis A, Pignon JP, Francois E, Chauffert B, Ichante JL, Boucher E, Ychou M, Pierga JY, Montoto-Grillot C, Conroy T: Efficacy and safety of bevacizumab-based combination regimens in patients with previously untreated metastatic colorectal cancer: final results from a randomised phase II study of bevacizumab plus 5-fluorouracil, leucovorin plus irinotecan versus bevacizumab plus capecitabine plus irinotecan (FNCLCC ACCORD 13/0503 study). Eur J Cancer 2013;49:1236-1245.

12 Maughan TS, Adams RA, Smith CG, et al: Addition of cetuximab to oxaliplatin-based first-line combination chemotherapy for treatment of advanced colorectal cancer: results of the randomised phase 3 MRC COIN trial. Lancet 2011;377:2103-2114.

13 Cunningham D, Lang I, Marcuello E, Lorusso V, Ocvirk J, Shin DB, Jonker D, Osborne S, Andre N, Waterkamp D, Saunders MP: Bevacizumab plus capecitabine versus capecitabine alone in elderly patients with previously untreated metastatic colorectal cancer (AVEX): an open-label, randomised phase 3 trial. Lancet Oncol 2013;14:1077-1085.

14 Van Cutsem E, Kohne CH, Lang I, Folprecht G, Nowacki MP, Cascinu S, Shchepotin I, Maurel J, Cunningham D, Tejpar S, Schlichting M, Zubel A, Celik I, Rougier P, Ciardiello F: Cetuximab plus irinotecan, fluorouracil, and leucovorin as first-line treatment for metastatic colorectal cancer: updated analysis of overall survival according to tumor KRAS and BRAF mutation status. J Clin Oncol 2011;29:2011-2019.
5 Bokemeyer C, Bondarenko I, Hartmann JT, de Braud F, Schuch G, Zubel A, Celik I, Schlichting M, Koralewski P: Efficacy according to biomarker status of cetuximab plus FOLFOX-4 as first-line treatment for metastatic colorectal cancer: the OPUS study. Ann Oncol 2011;22:1535-1546.

16 Douillard JY, Oliner KS, Siena S, et al: PanitumumabFOLFOX4 treatment and RAS mutations in colorectal cancer. N Engl J Med 2013;369:1023-1034.

17 Hurwitz H, Fehrenbacher L, Novotny W, Cartwright T, Hainsworth J, Heim W, Berlin J, Baron A, Griffing S, Holmgren E, Ferrara N, Fyfe G, Rogers B, Ross R, Kabbinavar F: Bevacizumab plus irinotecan, fluorouracil, and leucovorin for metastatic colorectal cancer. N Engl J Med 2004;350:2335-2342.

18 Folprecht G, Seymour MT, Saltz L, Douillard JY, Hecker H, Stephens RJ, Maughan TS, Van Cutsem E, Rougier P, Mitry E, Schubert U, Kohne CH: Irinotecan/fluorouracil combination in first-line therapy of older and younger patients with metastatic colorectal cancer: combined analysis of 2,691 patients in randomized controlled trials. J Clin Oncol 2008;26:14431451

19 Stintzing S, Jung A, Rossius L, Modest DP, Fischer von Weikersthal L, Decker T, Kiani A, Al-Batran S-E, Vehling-Kaiser U, Heintges T, Moehler M, Scheithauer W, Kirchner T, Heinemann V: Mutations within the EGFR signaling pathway: influence on efficacy in FIRE-3 - a randomized phase III study of FOLFIRI plus cetuximab or bevacizumab as first-line treatment for wild-type (WT) KRAS (exon 2) metastatic colorectal cancer (mCRC) patients. J Clin Oncol 2014; 32(suppl 3):abstr 445.

20 Rowland A, Dias MM, Wiese MD., Kichenadasse G, McKinnon RA, Karapetis CS, Sorich MJ: Meta-analysis comparing the efficacy of anti-EGFR monoclonal antibody therapy between KRAS G13D and other KRAS mutant metastatic colorectal cancer tumours. Eur J Cancer 2016;55:122-130.

21 Tejpar S, Celik I, Schlichting M, Sartorius U, Bokemeyer C, Van Cutsem E: Association of KRAS G13D tumor mutations with outcome in patients with metastatic colorectal cancer treated with first-line chemotherapy with or without cetuximab. J Clin Oncol 2012; 30:3570-3577. 
22 Tol J, Nagtegaal ID, Punt CJ: BRAF mutation in metastatic colorectal cancer. N Engl J Med 2009;361:98-99.

23 Kubicka S, Greil R, Andre T, Bennouna J, Sastre J, Van Cutsem E, von Moos R, Osterlund P, Reyes-Rivera I, Muller T, Makrutzki M, Arnold D: Bevacizumab plus chemotherapy continued beyond first progression in patients with metastatic colorectal cancer previously treated with bevacizumab plus chemotherapy: ML18147 study KRAS subgroup findings. Ann Oncol 2013;24: 2342-2349.

24 Heinemann V, Stintzing S, Modest DP, Giessen-Jung C, Michl M, Mansmann UR: Early tumour shrinkage (ETS) and depth of response (DpR) in the treatment of patients with metastatic colorectal cancer (mCRC). Eur J Cancer 2015;51:1927-1936.

25 Nordlinger B, Sorbye H, Glimelius B, Poston GJ, Schlag PM, Rougier P, Bechstein WO, Primrose JN, Walpole ET, Finch-Jones M, Jaeck D, Mirza D, Parks RW, Collette L, Praet M, Bethe U, Van Cutsem E, Scheithauer W, Gruenberger T: Perioperative chemotherapy with FOLFOX4 and surgery versus surgery alone for resectable liver metastases from colorectal cancer (EORTC Intergroup trial 40983): a randomised controlled trial. Lancet 2008;371:1007-1016.

26 Mitry E, Fields AL, Bleiberg H, Labianca R, Portier G, Tu D, Nitti D, Torri V, Elias D, O’Callaghan C, Langer B, Martignoni G, Bouche O, Lazorthes F, Van Cutsem E, Bedenne L, Moore MJ, Rougier P: Adjuvant chemotherapy after potentially curative resection of metastases from colorectal cancer: a pooled analysis of two randomized trials. J Clin Oncol 2008;26:4906-4911.

27 Primrose J, Falk S, Finch-Jones M, et al: Systemic chemotherapy with or without cetuximab in patients with resectable colorectal liver metastasis: the New EPOC randomised controlled trial. Lancet Oncol 2014; 15:601-611.

28 Arnold D, Graeven U, Lerchenmuller C, Killing B, Depenbusch R, Steffens C-C, Al-Batran S-E, Lange T, Dietrich G, Stoehlmacher J, Tannapfel A, Schmoll HJ, Reinacher-Schick A, Hegewisch-Becker S: Maintenance strategy with fluoropyrimidines (FP) plus Bevacizumab (Bev), Bev alone, or no treatment, following a standard combination of FP, oxaliplatin (Ox), and Bev as first-line treatment for patients with metastatic colorectal cancer (mCRC): a phase III non-inferiority trial (AIO KRK 0207). J Clin Oncol 2014;32(suppl):abstr 3503.

29 Simkens LH, van Tinteren H, May A, ten Tije AJ, Creemers GJ, Loosveld OJ, de Jongh FE, Erdkamp FL, Erjavec Z, van der Torren AM, Tol J, Braun HJ, Nieboer P, van der Hoeven JJ, Haasjes JG, Jansen RL, Wals J, Cats A, Derleyn VA, Honkoop AH, Mol L, Punt CJ, Koopman M: Maintenance treatment with capecitabine and bevacizumab in metastatic colorectal cancer (CAIRO3): a phase 3 randomised controlled trial of the Dutch Colorectal Cancer Group. Lancet 2015;385: 1843-1852.

30 Giantonio BJ, Catalano PJ, Meropol NJ, O’Dwyer PJ, Mitchell EP, Alberts SR, Schwartz MA, Benson AB 3rd: Bevacizumab in combination with oxaliplatin, fluorouracil, and leucovorin (FOLFOX4) for previously treated metastatic colorectal cancer: results from the Eastern Cooperative Oncology Group Study E3200. J Clin Oncol 2007;25:1539-1544.
31 Bennouna J, Sastre J, Arnold D, Osterlund P, Greil R, Van Cutsem E, von Moos R, Vieitez JM, Bouche O, Borg C, Steffens CC, Alonso-Orduna V, Schlichting C, Reyes-Rivera I, Bendahmane B, Andre T, Kubicka S: Continuation of bevacizumab after first progression in metastatic colorectal cancer (ML18147): a randomised phase 3 trial. Lancet Oncol 2013;14:29-37.

32 Van Cutsem E, Tabernero J, Lakomy R, Prenen H, Prausova J, Macarulla T, Ruff P, van Hazel GA, Moiseyenko V, Ferry D, McKendrick J, Polikoff J, Tellier A, Castan R, Allegra C: Addition of aflibercept to fluorouracil, leucovorin, and irinotecan improves survival in a phase III randomized trial in patients with metastatic colorectal cancer previously treated with an oxaliplatin-based regimen. J Clin Oncol 2012;30:34993506.

33 Tabernero J, Yoshino T, Cohn AL, Obermannova R, Bodoky G, Garcia-Carbonero R, Ciuleanu TE, Portnoy DC, Van Cutsem E, Grothey A, Prausova J, Garcia-Alfonso P, Yamazaki K, Clingan PR, Lonardi S, Kim TW, Simms L, Chang SC, Nasroulah F: Ramucirumab versus placebo in combination with second-line FOLFIRI in patients with metastatic colorectal carcinoma that progressed during or after first-line therapy with bevacizumab, oxaliplatin, and a fluoropyrimidine (RAISE): a randomised, double-blind, multicentre, phase 3 study. Lancet Oncol 2015;16:499-508.

34 Van Cutsem E, Peeters M, Siena S, Humblet Y, Hendlisz A, Neyns B, Canon JL, Van Laethem JL, Maurel J, Richardson G, Wolf M, Amado RG: Open-label phase III trial of panitumumab plus best supportive care compared with best supportive care alone in patients with chemotherapy-refractory metastatic colorectal cancer. J Clin Oncol 2007;25:1658-1664.

35 Grothey A, Van Cutsem E, Sobrero A, Siena S, Falcone A, Ychou M, Humblet Y, Bouche O, Mineur L, Barone C, Adenis A, Tabernero J, Yoshino T, Lenz HJ, Goldberg RM, Sargent DJ, Cihon F, Cupit L, Wagner A, Laurent D: Regorafenib monotherapy for previously treated metastatic colorectal cancer (CORRECT): an international, multicentre, randomised, placebo-controlled, phase 3 trial. Lancet 2013;381:303-312.

36 Santini D, Vincenzi B, Addeo R, Garufi C, Masi G, Scartozzi M, Mancuso A, Frezza AM, Venditti O, Imperatori M, Schiavon G, Bronte G, Cicero G, Recine F, Maiello E, Cascinu S, Russo A, Falcone A, Tonini G: Cetuximab rechallenge in metastatic colorectal cancer patients: how to come away from acquired resistance? Ann Oncol 2012;23:2313-2318.

37 Chibaudel B, Bonnetain F, Tournigand C, de Larauze $\mathrm{MH}$, de Gramont A, Laurent-Puig P, Paget J, Hadengue A, Notelet D, Benetkiewicz M, Andre T, de Gramont A: STRATEGIC-1: a multiple-lines, randomized, open-label GERCOR phase III study in patients with unresectable wild-type RAS metastatic colorectal cancer. BMC Cancer 2015;15:496.

38 Prahallad A, Sun C, Huang S, Di Nicolantonio F, Salazar R, Zecchin D, Beijersbergen RL, Bardelli A, Bernards R: Unresponsiveness of colon cancer to BRAF(V600E) inhibition through feedback activation of EGFR. Nature 2012;483:100-103.

39 Kopetz S, Desai J, Chan E, Hecht JR, O’Dwyer PJ, Maru D, Morris V, Janku F, Dasari A, Chung W, Issa JP, Gibbs P, James B, Powis G, Nolop KB, Bhattacharya S, Saltz L: Phase II pilot study of vemurafenib in patients with metastatic BRAF-mutated colorectal cancer. J Clin Oncol 2015;33:4032-4038.
40 Yaeger R, Cercek A, O’Reilly EM, Reidy DL, Kemeny N, Wolinsky T, Capanu M, Gollub MJ, Rosen N, Berger MF, Lacouture ME, Vakiani E, Saltz LB: Pilot trial of combined BRAF and EGFR inhibition in BRAF-mutant metastatic colorectal cancer patients. Clin Cancer Res 2015;21:1313-1320.

41 Atreya C, Van Cutsem E, Bendell JC, Andre T, Schellens JHM, Gordon MS, McRee AJ, O’Dwyer PJ, Muro K, Tabernero J, van Geel R, Sidhu RJ, Greger JG, Rangwala FA, Motwani M, Wu Y, Orford KW, Corcoran RB: Updated efficacy of the MEK inhibitor trametinib (T), BRAF inhibitor dabrafenib (D), and anti-EGFR antibody panitumumab (P) in patients (pts) with BRAF V600E mutated (BRAFm) metastatic colorectal cancer (mCRC). J Clin Oncol 2015;33(suppl):abstr 103.

42 Topalian SL, Hodi FS, Brahmer JR, et al: Safety, activity, and immune correlates of anti-PD-1 antibody in cancer. N Engl J Med 2012;366:2443-2454.

43 Le DT, Uram JN, Wang H, et al: PD-1 blockade in tumors with mismatch-repair deficiency. N Engl J Med 2015;372:2509-2520.

44 Siena S, Sartore-Bianchi A, Lonardi S, Trusolino L, Martino C, Bencardino K, Leone F, Zagonel V, Valtorta E, Torri V, Siravegna G, Amatu A, Bonazzina EF, Rusconi F, Ghezzi S, Ciardiello F, Veronese S, Comoglio PM, Bardelli A, Marsoni S: Trastuzumab and lapatinib in HER2-amplified metastatic colorectal cancer patients (mCRC): the HERACLES trial. J Clin Oncol 2015;33(suppl):abstr 3508.

45 Heinemann V, von Weikersthal LF, Decker T, et al: FOLFIRI plus cetuximab versus FOLFIRI plus bevacizumab as first-line treatment for patients with metastatic colorectal cancer (FIRE-3): a randomised, openlabel, phase 3 trial. Lancet Oncol 2014;15:1065-1075.

46 Stintzing S, Jung A, Rossius L, Modest DP, Fischer von Weikersthal L, Decker T, Möhler M, Scheithauer W, Kirchner T, Heinemann V: Analysis of KRAS/NRAS and BRAF mutations in FIRE-3: a randomized phase III study of FOLFIRI plus cetuximab or bevacizumab as first-line treatment for wild-type (WT) KRAS (exon 2) metastatic colorectal cancer (mCRC) patients. $\mathrm{ECCO} /$ ESMO 2013;LBA17.

47 Lenz HJ, et al: CALGB/SWOG 80405: phase III trial of irinotecan/5-FU/leucovorin (Folfiri) or oxaliplatin/5FU/leucovorin (mFOLFOX6) with bevacizumab (bv) or cetuximab (cet) for patients (pts) with expanded Ras analyses in untreated metastatic adenocarcinoma of the colon or rectum (MCRC). Ann Oncol 2014;25 (suppl 4):501O.

48 Schwartzberg LS, Rivera F, Karthaus M, Fasola G, Canon JL, Hecht JR, Yu H, Oliner KS, Go WY: PEAK: a randomized, multicenter phase II study of panitumumab plus modified fluorouracil, leucovorin, and oxaliplatin (mFOLFOX6) or bevacizumab plus mFOLFOX6 in patients with previously untreated, unresectable, wild-type KRAS exon 2 metastatic colorectal cancer. J Clin Oncol 2014;32:2240-2247. 